Krystina B. Lewis*, Ian D. Graham, Laura Boland and Dawn Stacey

\title{
Writing a compelling integrated discussion: a guide for integrated discussions in article-based theses and dissertations
}

https://doi.org/10.1515/ijnes-2020-0057

Received June 16, 2020; accepted January 8, 2021; published online March 1, 2021

\begin{abstract}
Article-based theses and dissertations are increasingly being used in nursing and the health sciences as an alternate format to the traditional five-chapter monograph. A unique chapter in the article-based thesis is the integrated discussion, which differs in breadth and depth as compared to the discussion for a traditional thesis monograph or journal article. For many students and faculty, the integrated discussion is a challenging chapter to write, with minimal or no published guidance available. In this article, we offer a fourstep approach with templates for planning and writing an integrated discussion. We also share several lessons learned with examples from published theses and dissertations. Writing an integrated discussion can be facilitated and written more efficiently by developing a clear and detailed outline of the chapter and broad discussion points prior to drafting the text, to achieve a higher-level synthesis, analysis, and interpretation of the overall significance of the thesis findings.
\end{abstract}

Keywords: academic dissertation; graduate education; scholarly communication; thesis-by-article; writing.

\section{Introduction}

An increasing number of university graduate programs in nursing and the health sciences offer the option of writing an article-based thesis or dissertation as an alternate format to the traditional five-chapter monograph (De Jong, Moser, \& Hall, 2005; Graves et al., 2018; Robinson \& Dracup, 2008; Smaldone, Heitkemper, Jackman, Joanne Woo, \& Kelson, 2019). This format has gained traction internationally to facilitate the earlier and more frequent publication of graduate student research for the timelier advancement of knowledge and impact on clinical practice (Evans, Amaro, Herbert, Blossom, \& Roberts, 2018; Maynard, Vaughn, Sarteschi, \& Berglund, 2012; Smaldone et al., 2019). An article-based thesis, also known as the manuscript option, thesis-by manuscript, integrated thesis, or $\mathrm{PhD}$ by published works, typically includes one or more articles suitable for publication in peer-reviewed journals and bounded together with an introduction chapter and integrated discussion chapter (Baggs, 2011). The integrated discussion is a unique chapter in an article-based thesis. Integrated (2020) is defined as "many different parts [that] are closely connected and work successfully together" ("Integrated," 2020). The general purpose of the integrated discussion chapter is to provide an overall synthesis and demonstrate high level abstraction, analysis, and interpretation of the thesis findings. It is an

*Corresponding author: Krystina B. Lewis, RN, MN, PhD, Assistant Professor, School of Nursing, Faculty of Health Sciences, University of Ottawa, Roger Guindon Hall - 1118B, 451 Smyth Road, Ottawa, ON K1H 8M5, Canada; and Affiliate Researcher, University of Ottawa Heart Institute, Ottawa, ON, Canada, Phone: +1 6135625800 ext. 8654, Fax: +1 6135625443 , E-mail: Krystina.Lewis@uottawa.ca

Ian D. Graham, School of Epidemiology \& Public Health, University of Ottawa, Ottawa, Canada; and Ottawa Hospital Research Institute, Ottawa, Canada

Laura Boland, and Ottawa Hospital Research Institute, Ottawa, Canada; and Western University, London, Canada

Dawn Stacey, School of Nursing, University of Ottawa, Ottawa, ON, Canada; and Ottawa Hospital Research Institute, Ottawa, Canada

Ә Open Access. @ 2021 Krystina B. Lewis et al., published by De Gruyter. (C) BY This work is licensed under the Creative Commons Attribution 4.0 International License. 
opportunity to showcase the thesis' findings, the student's reflections about the findings, and its implications (Smith, 2015).

Requirements and expectations for the integrated discussion chapter vary by institution and department. Supervising faculty within individual institutions may also have differing approaches and expectations. We found no general rules or expectations in the literature for writing an integrated discussion. An inquiry of select institutional guidance documents in various international jurisdictions revealed that academic institutions provide few details about this chapter. Descriptions focus more on the overall contribution of the integrated discussion chapter to the thesis, rather than guidance on how to write it (Table 1).

Writing a compelling integrated discussion can be challenging, and there is a scarcity of resources, instructions, or published guidance for students and supervising faculty on this subject. Existing guidance is focused primarily on writing discussions for a single journal article or a traditional thesis monograph. Yet, the integrated discussion chapter differs in breadth and depth. In journal articles, a discussion usually consists of a statement of the main findings, interpretation of the results in the context of the broader literature, strengths

Table 1: Examples of institutional guidelines for the integrated discussion chapter in an article-based thesis.

\begin{tabular}{|c|c|c|}
\hline Country & Institution & Description as included in institutional guidelines \\
\hline Australia & Deakin University & $\begin{array}{l}\text { "The thesis must be an integrated and coherent whole. The thesis must include ... a section } \\
\text { which describes how all the publications are linked (possibly more than one such section), } \\
\text { and a conclusion which provides a synthesis of all the material. The conclusion is important } \\
\text { and needs to be of a very high standard. It is not just a summary of the thesis. This is your } \\
\text { chance to really tell the examiners about the significance ofyour work, how it all fits together } \\
\text { as a coherent body, how it demonstrates originality, and how it can lead to future } \\
\text { research."(Deakin University, 2019, para. 10) }\end{array}$ \\
\hline Canada & University of Ottawa & $\begin{array}{l}\text { "An integrated discussion is an explicit weaving together of the content across the article(s)/ } \\
\text { other sections of the thesis ... Integrated discussion, with conclusions, to integrate study } \\
\text { findings across article(s) (or with other sections of the thesis, such as the literature review, } \\
\text { in the case of a single-article thesis) with extant literature and discuss implications for } \\
\text { nursing and contributions to nursing knowledge (e.g., practice, education, theory, policy, } \\
\text { research)."(University of Ottawa, 2020, p. 2) }\end{array}$ \\
\hline Denmark & Aarhus University & $\begin{array}{l}\text { "The review should normally contain the following [as related to the integrated discussion]: } \\
\text { - Brief presentation of the most important results } \\
\text { - In-depth discussion of the results in the light of a critical evaluation of the basic theories } \\
\text { and the methodologies used; and } \\
\text { - Section discussing future aspects, if applicable" (Aarhus University, 2020, para. 5) }\end{array}$ \\
\hline South Africa & $\begin{array}{l}\text { Stellenbosch } \\
\text { University }\end{array}$ & $\begin{array}{l}\text { "A discussion chapter of the research results of the whole dissertation, highlighting the } \\
\text { scientific contributions of the study, followed by a conclusion and future directions ... The } \\
\text { purpose of the discussion chapter is to interpret the meaning of the results within the context } \\
\text { of what is known about the topic. New insights based on the findings should be explained. } \\
\text { The discussion will consist of argumentation as different perspectives and explanations are } \\
\text { considered. This chapter could include limitations and recommendations for future } \\
\text { research."(Stellenbosch University, 2019, p. 8) }\end{array}$ \\
\hline $\begin{array}{l}\text { United } \\
\text { Kingdom }\end{array}$ & Lancaster University & $\begin{array}{l}\text { "A supporting paper: this should summarize each publication submitted, outline their } \\
\text { interrelationship, give a critical review of the current state of knowledge and research in the } \\
\text { applicant's field and indicate how his or her work has contributed to the field." (Lancaster } \\
\text { University, 2020, p. 40) }\end{array}$ \\
\hline United States & $\begin{array}{l}\text { University of } \\
\text { Pennsylvania }\end{array}$ & $\begin{array}{l}\text { "A final discussion chapter should synthesize dissertation findings for all aims/questions, } \\
\text { describe and interpret the significance of the overall dissertation results, and identify } \\
\text { implications for research and practice that stem from the entire dissertation. It is important } \\
\text { that this chapter show how separate findings presented in distinct papers contribute to an } \\
\text { integrated body of knowledge that addresses the overall purpose of the dissertation } \\
\text { research." (University of Pennsylvania School of Nursing, n.d., "Dissertation Format") }\end{array}$ \\
\hline
\end{tabular}


and limitations of the study, and implications for potential users of the findings (clinicians, administrators, policy makers, and others), the discipline, and future research (Makar, Foltz, Lendner, \& Vaccaro, 2018). The discussion section of the traditional monograph thesis has a similar format to that of a journal article as it discusses a single study but is often more detailed. In comparison, the integrated discussion chapter of the article-based thesis provides students with a space in which to weave the results and discussion points from the individual articles comprising the thesis, elaborate on the logic and linkages between them, and convincingly argue for the unified, coherent, and original nature of their findings and contributions to the fieldat-large. Smith (2015) refers to this as the golden thread. Grant (2011) refers to it as the logic of connectivity. Ultimately, it is about how the student links the key ideas from the individual papers and articulates the connectedness between them, so as to make readers understand the thesis' broader meaning which make it accessible to a larger audience (Smith, 2015).

The educational value of conceptualizing and writing an integrated discussion can be best classified at the highest level of Bloom's revised taxonomy of educational objectives, to Create - formerly known as Synthesis in Bloom's original taxonomy - whereby parts are combined in novel ways to produce a coherent whole and to formulate new points of view (Anderson \& Krathwohl, 2001; Bloom, 1956). According to the taxonomy, the integrated discussion represents the pinnacle of cognitive tasks and processes by requiring higher-order thinking and critical reflections expected of graduate level students. Hence, the integrated discussion chapter provides the graduate student an opportunity to synthesize, integrate, and raise the discussion to a higher level of abstraction; allowing them to demonstrate the coherence between all articles reported in the thesis. It is often in the integrated discussion where thesis advisory committee members and examiners can assess the student's depth of theoretical and applied knowledge of the subject matter, capacity for critical inquiry, and judge the overall value of the student's conclusions and contributions to the substantive area of study (Gould, 2016). Specifically in nursing, this higher-level thinking can be articulated by discussing how the knowledge generated advances nursing practice, education and research, and how it contributes to the delivery of high quality health care, and improved health and health system outcomes (Institute of Medicine [US] Committee on the Robert Wood Johnson Foundation Initiative on the Future of Nursing, 2011). Yet, with little guidance available on how to think about and write an integrated discussion, graduate students may miss the opportunity to engage in this higher-order thinking and critical reflections.

In this paper, we offer a practical four-step approach with templates for writing an integrated discussion for article-based theses. KBL initially developed the steps and templates as she conceptualized and wrote her integrated discussion for her $\mathrm{PhD}$ dissertation. The steps and templates were refined as a result of (a) her own integrated discussion writing process; (b) discussion with her thesis supervisor and thesis advisory committee members; and, (c) feedback from several graduate students who have used it successfully. As recent doctoral graduates and faculty supervisors, we are sharing this approach and our lessons learned with examples from published theses and dissertations.

\section{Writing an integrated discussion chapter}

\section{Step 1: Outlining the integrated discussion chapter}

To begin, we propose drafting an outline for the integrated discussion chapter with six major sections (Table 2). First, provide an opening paragraph introducing the information to be presented in the chapter. Second, present a summary of the overall purpose of the thesis as a unified piece of work and a brief summary of each individual article prepared for publication. Each article summary should include the study aim, study design, and key results. Keep in mind that by the time supervisors, thesis advisory committee members, and examiners read the integrated discussion chapter, they have probably just finished reading the previous chapters and articles, so there is no need to repeat information in detail. Rather, the purpose of this section is to refresh the readers' focus and to begin demonstrating how the articles logically link to each other. Third, outline the main points of the integrated discussion as clearly and concisely as possible (see Step 2 and 3 for more details). 
Table 2: Suggested structure for an integrated discussion.

\begin{tabular}{ll}
\hline Sections & Suggested length $^{\mathrm{a}}$ \\
\hline - Introduction to the chapter & $1 / 4$ to $1 / 2$ page \\
- Summary of the overall purpose of the dissertation and main findings from each of the included & $1 / 2$ to 1 page each \\
articles & \\
- Main points of integrated discussion & Variable (1-2 pages for each) \\
- Strengths and limitations of the dissertation (if applicable and beyond the individual articles) & Variable \\
- Disciplinary implications (e.g., practice, education, leadership, and/or policy, and research) & Variable and may include a \\
& table \\
- Conclusions from the dissertation overall & $1 / 4$ to $1 / 2$ page \\
\hline
\end{tabular}

${ }^{a}$ Approximate length based on 12-point type font, double spacing, left-justified, 1 -inch margins, and format for $81 / 2 \times 11$ paper.

Fourth, discuss the strengths and limitations of the thesis, as a whole, if applicable. Typically, strengths and limitations are only presented at the individual article level, but if there are broader strengths or limitations that apply to the thesis, they can be discussed in this chapter. Fifth, discuss the implications of the thesis for the specific discipline (e.g., nursing, medicine, population health, epidemiology, rehabilitation) in terms of the findings' applicability to practice, education, leadership, and/or policy. Sixth, describe implications for future research. Finally, this chapter should end with a strong, clear, and logical conclusion summarizing the entire work across all elements of the thesis. The conclusions should clearly state the original contribution(s) to the advancement of knowledge and overall significance for the field at-large.

\section{Step 2. Mapping individual articles' findings to inform the integrated discussion}

The next step is to draft the main integrated discussion points. Using Template I, capture the main discussion points from each individual article (Table 3). If there is only one article in the thesis, these can be generated

Table 3: Template I to summarize individual article discussion points to identify overarching discussion points.

\begin{tabular}{|c|c|c|c|c|}
\hline \multicolumn{5}{|c|}{ Summary of discussion points from individual articles ${ }^{a}$} \\
\hline $\begin{array}{l}\text { Discussion points } \\
\text { Article A }\end{array}$ & $\begin{array}{l}\text { Discussion points } \\
\text { Article B }\end{array}$ & $\begin{array}{l}\text { Discussion points } \\
\text { Article } C\end{array}$ & $\begin{array}{l}\text { Discussion points } \\
\text { Other articles }\end{array}$ & $\begin{array}{l}\text { Preliminary overarching } \\
\text { points for integrated discussion }\end{array}$ \\
\hline A.1 & B.1 & C.1 & $\ldots$ & ID.1 \\
\hline A. 2 & B.2 & C.2 & $\ldots$ & ID.2 \\
\hline A.3 & B. 3 & C.3 & $\ldots$ & ID.3 \\
\hline Etc. & Etc. & Etc. & Etc. & Etc. \\
\hline \multicolumn{5}{|c|}{ Summary of disciplinary implications from individual articles ${ }^{a, b}$} \\
\hline Implications & Implications & Implications & Implications & Summary for integrated discussion \\
\hline Article $\mathrm{A}$ & Article B & Article C & Other articles & \\
\hline Practice: & Practice: & Practice: & Practice: & Practice: \\
\hline Education: & Education: & Education: & Education: & Education: \\
\hline Leadership: & Leadership: & Leadership: & Leadership: & Leadership: \\
\hline Policy: & Policy: & Policy: & Policy: & Policy: \\
\hline Research: & Research: & Research: & Research: & Research: \\
\hline
\end{tabular}

af there is only one article in the thesis, additional discussion points/contributions/implications can come from the literature review, guiding theoretical framework, and/or chosen methodology. ${ }^{b}$ Whether these implications are included in the individual article or not, this explicitly offers a starting point to think of the implications arising from individual articles. 
from the literature review, guiding theoretical framework, and/or chosen methodology. This exercise is intended to facilitate the student's thinking about how to build convincing overarching discussion points and explore the key messages they want readers to come away with after reading the thesis.

The last row in this template is reserved for listing the actual and potential disciplinary implications arising from each article, which may address any of the following domains: practice, education, leadership, policy and/or research. Depending on journal requirements, these implications may be directly discussed in the individual articles. If not, this section offers the student a starting point for thinking about the disciplinary implications arising from their thesis as a whole.

Completing Template I as individual articles are finalized, and sharing it with a faculty supervisor or thesis advisory committee can facilitate discussion about the evolving integrated discussion points. It can also facilitate requisite critical thinking and reflection necessary for linking findings across the individual articles.

\section{Step 3. Drafting the main integrated discussion points}

Using Template II (Table 4), begin by listing the integrated discussion points identified in Template I (Table 3). From these, identify supporting (or refuting) arguments from the individual articles. Concurrently, identify broader literature sources to incorporate into the integrated discussion. For those who are more visual, this template can also take the form of mind maps, flow charts, or Venn diagrams (Carter, 2009). To facilitate the identification of the broader integrated discussion points, this step can be broken down further into the following sub-steps:

1) Consider the discussion points and disciplinary implications across all individual articles of the thesis to identify commonalities or differences;

2) Draft main integrated discussion points, logically connecting the individual articles;

3) Identify findings from, ideally, two individual articles that support (or refute) the proposed main integrated discussion points (aiming for evidence from two articles helps achieve a higher level integrated discussion); and

4) Identify and classify theoretical and empirical literature relevant to the main integrated discussion points. Select regional, national, and international empirical studies, theoretical works, clinical practice

Table 4: Template II to build the main integrated discussion points from the individual articles and summarize implications.

\begin{tabular}{|c|c|c|c|}
\hline $\begin{array}{l}\text { Integrated } \\
\text { discussion points }\end{array}$ & $\begin{array}{l}\text { Supporting (or refuting) contributions/ } \\
\text { arguments from individual articles }^{\mathrm{a}}\end{array}$ & $\begin{array}{l}\text { Link to broader } \\
\text { literature/key references }{ }^{b}\end{array}$ & $\begin{array}{l}\text { Summary of disciplinary implica- } \\
\text { tions arising from the dissertation }\end{array}$ \\
\hline ID1. & $\begin{array}{l}\text { What does Article A contribute? } \\
\text { What does Article B contribute? } \\
\text { What does Article C contribute? } \\
\text { Etc. }\end{array}$ & & $\begin{array}{l}\text { Practice (discipline specific): } \\
\text { Education: } \\
\text { Leadership: } \\
\text { Policy: } \\
\text { Other: }\end{array}$ \\
\hline ID2. & $\begin{array}{l}\text { What does Article A contribute? } \\
\text { What does Article B contribute? } \\
\text { What does Article C contribute? } \\
\text { Etc. }\end{array}$ & & Research: \\
\hline ID3. & $\begin{array}{l}\text { What does Article A contribute? } \\
\text { What does Article B contribute? } \\
\text { What does Article C contribute? } \\
\text { Etc. }\end{array}$ & & \\
\hline Other & $\ldots$ & $\ldots$ & $\ldots$ \\
\hline
\end{tabular}

${ }^{a}$ If there is only one article in the thesis, the supporting contributions/arguments can come from the literature review, guiding theoretical framework, and/or chosen methodology. ${ }^{b}$ Broader literature can include empirical studies, theoretical works, practice guidelines, technical reports, and/or policy documents. 'List the disciplinary implications identified across all articles. This explicitly offers a starting point to think of the disciplinary implications arising across the individual articles' findings and discussion points. 
guidelines, technical reports, and/or policy documents; highlight what the thesis adds to the field (of knowledge) and how it will enhance understanding of the subject.

This exercise is intended to help organize the content of the integrated discussion early in the writing process. We recommend sharing the evolving Templates I and II with the faculty supervisor or thesis advisory committee and use it as a tool for discussion before writing the integrated discussion chapter. As supervisors (DS, IDG), we also initiate Template I in discussion with our graduate students - often using a blank piece of paper. This reflective exercise may save time in the long run, as it facilitates staying focused on the key points and avoids repeating elements of the discussions within the individual papers. The more detailed the completed templates, the more content is available to transform into text.

\section{Step 4. Writing the integrated discussion chapter}

The final step is to turn the planned outline (Step 1) and the drafted main integrated discussion points (Step 3) into narrative prose. To remain focused, start by adding subheadings from the outline and lower level subheadings for each of the main integrated discussion points. A compelling integrated discussion is often preceded by multiple revisions. It should not be written when rushing to meet the thesis submission deadline as writing this chapter requires considerable reflection and introspection. For these reasons, we remind students that the integrated discussion is the last chapter their examiners will read, and it will leave a lasting impression. Getting this chapter right allows the student to demonstrate their mastery of the totality of their thesis work and sets the stage for the examination. In our experience, when an integrated discussion is wellwritten, the examiners' comments indicate that the integrated discussion chapter tied all elements of the thesis together and helped them understand the thesis in its entirety.

\section{Lessons learned}

When applying this approach for writing our own integrated discussions, or when guiding graduate students through the process, we have learned several lessons. To exemplify these lessons, we offer examples of published theses and dissertations in nursing and other health professions.

\section{Lesson 1. Use stepwise approach with templates to plan and structure the chapter}

Using the attached templates and proposed stepwise approach to structure the writing process reduces the inclination to simply repeat the discussion points found in the individual articles. The templates may also help graduate students overcome procrastination resulting from not knowing where to start with the integrated discussion. Further, Templates I and II may be used to guide discussions between graduate student and faculty supervisor, allowing for progress to be monitored prior to writing. Another advantage to doing this early is that some supervisors are less familiar with the article-based thesis format and may have little experience guiding their students in writing the integrated discussion. As such, using the template to walk through this process may be helpful for both parties.

\section{Lesson 2. Think ahead}

Avoid delaying until all the individual thesis articles are written before thinking about the integrated discussion. We recommend filling out the templates as individual articles are completed. When analyzing the results for individual articles and thinking about the discussion sections for these, we often identified relevant discussion points that were too broad for the articles. Keeping a log of discussions with faculty supervisors and 
thesis advisory committee members throughout the thesis writing process, and keeping record of personal reflections that were beyond the scope of individual articles, may help gather ideas early. For example, when first considering her integrated discussion, Hoefel (2019) chose the Walker and Avant (2011) theory testing approach to validate the decisional needs concept and test the main hypothesis of the Ottawa Decision Support Framework (O'Connor et al., 1998). For her thesis, Hoefel (2019) wrote two articles based upon this framework. Her first was a systematic review article on decisional needs of people making health decisions and the second was a sub-analysis of a systematic review on patient decision aids. Hence, evidence from these articles contributed to the higher level discussion about validating the concepts and testing the hypotheses in the framework.

\section{Lesson 3. Dedicate sufficient time}

Dedicating sufficient time to writing the integrated discussion is important. For many students, the integrated discussion is a challenging chapter to write. It calls for a different style of writing than that which is required for individual research study articles. It requires conveying abstract and conceptual ideas to generate broader insights. Prior to developing and using these templates, our experience with many students has been that it can take many months of re-writing the integrated discussion chapter for it to adequately reflect the breadth and depth of the student's thesis work and its vital contribution to the field. We have found that our stepwise approach involves more careful planning and conceptualizing of the integrated discussion prior to drafting the chapter, and therefore results in a more efficient writing and editing process.

\section{Lesson 4. Consider theoretical and methodological implications}

Theoretical and methodological implications may be considered as integrated discussion points. A student may choose to closely examine their selected theoretical perspective in light of their thesis findings. For example, in Lewis' (2018) integrated discussion, she provided a discourse on the use of complementary theoretical frameworks across individual studies: the Ottawa Decision Support Framework (O'Connor et al., 1998) and Normalization Process Theory (May et al., 2009). This provided a link between intervention development and implementation planning, proposing a novel theory-informed approach for the development of decision support interventions (Lewis, 2018). Likewise, methodological implications may be discussed in cases where a student's thesis advances methods, or to discuss the influence of chosen methodology on key findings where similar research questions are answered using distinct study designs. Wu's (2014) integrated discussion focused on the methods used for conducting a survey for data collection. He used a set of reminders, with the last reminder being a courier package and return envelope. He then discussed how testing this reminder strategy in his thesis study contributed to survey design methods.

\section{Lesson 5. An integrated discussion is feasible with one article}

In cases where there is only one article comprising an article-based thesis, key findings from a more detailed literature review, a theoretical framework guiding the entire research project, or chosen methodology can provide the additional linkages to build the main integrated discussion points. For instance, in her Master of Nursing thesis integrated discussion, Demery Varin (2018) compared and contrasted her secondary analysis findings on the predictors of nurses' research use in long-term care settings (as reported in one published article) with her review of the literature on the individual and contextual factors to nurses' research use in all settings. 


\section{Lesson 6. Integrated discussions are publishable}

The integrated discussion (or elements of it) may be publishable in its own right. When written well, the integrated discussion often results in an important academic contribution to the body of knowledge. Some graduate students have used the integrated discussion as the basis for a commentary paper or an updated theoretical framework paper. In her integrated discussion chapter of her doctoral thesis, Jull (2014) described the development of a collaborative framework for community-research partnerships co-produced by First Nations, Inuit, and Metis women's community members and researchers. This framework was based on her findings and experience conducting the studies comprising her thesis. Jull et al. (2018) subsequently published a paper based on her integrated discussion.

\section{Lesson 7. Integrated discussions can lay the foundation for subsequent research}

Many students who are completing a Master's or PhD thesis also intend to pursue further research. A well thought out and articulated integrated discussion can inform subsequent research projects, grant proposals, or programs of research. For example, Boland (2018) drew from her PhD integrated discussion to identify evidence-practice gaps and potential solutions in pediatric shared decision-making, which she used to underpin a successful Canadian Institutes of Health Research post-doctoral fellowship and guide the establishment of her research program.

\section{Conclusion}

In this paper, we propose an approach to writing an integrated discussion chapter for an article-based thesis. Our advice provided in this paper is intended to position graduate students to adequately plan and produce a unified, coherent, and higher-level synthesis of the articles comprising their thesis. Challenges in writing an integrated discussion include avoiding repetition of discussion points already included within the individual articles comprising the thesis and achieving a higher-level discussion to integrate findings across the individual articles. Writing an integrated discussion can be facilitated by developing a clear and detailed outline of the chapter and, in particular, by identifying broader, more overarching points of discussion, than those presented within the individual articles. We encourage graduate students, faculty supervisors and thesis advisory committees to use the templates provided and share their experiences.

Acknowledgments: The authors wish to thank the graduate students who have used this approach, reported that it was useful, and offered feedback to improve it. The authors also wish to thank the reviewers. Their critical read and constructive comments strengthened this manuscript.

Research funding: The authors received no financial support for the authorship and publication of this manuscript. IDG is a recipient of a CIHR Foundation Grant (FDN\# 143237). DS holds a University Research Chair in Knowledge Translation to Patients at the University of Ottawa.

Author contributions: All authors have accepted responsibility for the entire content of this manuscript and approved its submission.

Competing interest: Authors state no conflict of interest.

\section{References}

Aarhus University. (2020). Guidelines for assessment of PhD dissertation and PhD defence. Retrieved from https://phd.health.au. $\mathrm{dk} /$ doingaphd/dissertation/assessment/guidelinesforassessmentofphddissertationandphddefence/.

Anderson, L. W., \& Krathwohl, D. R. (2001). A taxonomy for teaching, learning, and assessing: A revision of Bloom's taxonomy of educational objectives. New York, NY: Longman. 
Baggs, J. G. (2011). The dissertation manuscript option, internet posting, and publication. Research in Nursing \& Health, 34(2), 89-90.

Bloom, B. S. (1956). Taxonomy of educational objectives, handbook I: The cognitive domain. New York: David McKay Co Inc.

Boland, L. (2018). Implementation of shared decision making in pediatric clinical practice [PhD in Population Health]. Ottawa, Canada: University of Ottawa.

Carter. (2009). Old lamps for new: Mnemonic techniques and the thesis. Arts and Humanities in Education, 8, 56-68.

De Jong, M. J., Moser, D. K., \& Hall, L. A. (2005). The manuscript option dissertation: Multiple perspectives. Nurse Author \& Editor, 15(3), 3-4, 7-9.

Deakin University. (2019). Thesis structure options: Thesis by publication. Retrieved from https://www.deakin.edu.au/students/ research/your-thesis-and-examinations/thesis-structure-options.

Demery Varin, M. (2018). Modeling the predictors of nurses' research use in Canadian long-term care homes [Masters of Science degree in Nursing]. Ottawa, Canada: University of Ottawa.

Evans, S. C., Amaro, C. M., Herbert, R., Blossom, J. B., \& Roberts, M. C. (2018). “Are you gonna publish that?” Peer-reviewed publication outcomes of doctoral dissertations in psychology. PloS One, 13(2), e0192219.

Gould, J. (2016). Future of the thesis. Nature, 535, 26-28.

Grant, C. (2011). Diversifying and transforming the doctoral studies terrain: A student's experience of a thesis by publication. Alternation, 18(2), 245-267.

Graves, J. M., Postma, J., Katz, J. R., Kehoe, L., Swalling, E., \& Barbosa-Leiker, C. (2018). A national survey examining manuscript dissertation formats among nursing PhD programs in the United States. Journal of Nursing Scholarship, 50(3), 314-323.

Hoefel, L. (2019). 20th Anniversary update of the Ottawa Decision Support Framework: Evidence syntheses of needs assessments and trials of patient decision aids [Masters of Science degree in Nursing]. Ottawa, Canada: University of Ottawa.

Institute of Medicine Committee on the Robert Wood Johnson Foundation Initiative on the Future of Nursing. (2011). The future of nursing: Leading change, advancing health. Washington (DC): National Academies Press.

Integrated. (2020). https://www.oxfordlearnersdictionaries.com/definition/english/integrated [Accessed 3 Dec 2020].

Jull, J. (2014). Cultural adaptation of a shared decision-making intervention to address the needs of first Nations, Métis and Inuit women [PhD in Population Health]. Ottawa, Canada: University of Ottawa.

Jull, J., Giles, A., Boyer, Y., \& Stacey, D., \& Minwaashin Lodge. (2018). Development of a Collaborative Research Framework: An Example of a Study Conducted By and With a First Nations, Inuit and Métis Women's Community and Its Research Partners. ACME: An International Journal for Critical Geographies, 17(3), 671-686. https://acme-journal.org/index.php/acme/article/ view/1317.

Lancaster University. (2020). Manual of academic regulations and procedures: Postgraduate graduate research regulations. Retrieved from https://www.lancaster.ac.uk/media/lancaster-university/content-assets/documents/student-basedservices/asq/marp/PGR-Regs.pdf.

Lewis, K. B. (2018). Development and preliminary evaluation of decision support for patients to accept or decline implantable cardioverter-defibrillator replacement at the time of battery depletion [PhD in Nursing]. Ottawa, Canada: University of Ottawa.

Makar, G., Foltz, C., Lendner, M., \& Vaccaro, A. R. (2018). How to write effective discussion and conclusion sections. Clinical Spine Surgery, 31(8), 345-346.

May, C. R., Mair, F., Finch, T., MacFarlane, A., Dowrick, C., Treweek, S., ... Montori, V. M. (2009). Development of a theory of implementation and integration: Normalization process theory. Implementation Science, 4, 29.

Maynard, B. R., Vaughn, M. G., Sarteschi, C. M., \& Berglund, A. H. (2012). Social work dissertation research: Contributing to scholarly discourse or the file drawer? British Journal of Social Work, 44, 1045-1062.

O’Connor, A. M., Tugwell, P., Wells, G. A., Elmslie, T., Jolly, E., Hollingworth, G., ... Drake, E. (1998). A decision aid for women considering hormone therapy after menopause: Decision support framework and evaluation. Patient Education and Counseling, 33(3), 267-279.

Robinson, S., \& Dracup, K. (2008). Innovative options for the doctoral dissertation in nursing. Nursing Outlook, 56(4), $174-178$.

Smaldone, A., Heitkemper, E., Jackman, K., Joanne Woo, K., \& Kelson, J. (2019). Dissemination of PhD dissertation research by dissertation format: A retrospective cohort study. Journal of Nursing Scholarship, 51(5), 599-607.

Smith, S. (2015). PhD by published work: A practical guide for success. London, UK: Palgrave.

Stellenbosch University. (2019). General information on doctoral studies. [Available upon request].

University of Ottawa. (2020). Monograph thesis and thesis by article(s) - regulations. Retrieved from https://www.uottawa.ca/ graduate-studies/students/theses/writing.

University of Pennsylvania School of Nursing. (n.d.). PhD handbook. Retrieved from https://www.nursing.upenn.edu/studentservices/resources/handbooks-forms-policies/phd-handbook/dissertation/.

Walker, L. O., \& Avant, K. C. (2011). Strategies for theory construction in nursing. Boston: Prentice-Hall.

Wu, R. C. (2014). Evaluation of a rectal cancer patient decision aid and the factors influencing its implementation in clinical practice [Masters of Science in Epidemiology]. Ottawa, Canada: University of Ottawa. 